\title{
Analisis Persepsi dan Harapan Pelanggan Terhadap Kualitas Layanan Galeri Sangkring Art Space
}

\author{
Anggiansyah \\ Program Pascasarjana Institut Seni Indonesia Yogyakarta \\ anggeansyah@gmail.com
}

\begin{abstract}
Abstrak
Berbicara mengenai galeri sebagai salah satu jasa yang bergerak di bidang seni, erat kaitannya dengan pembahasan tentang kualitas layanannya. Setiap galeri yang ingin maju dan berkembang, dituntut untuk selalu meningkatkan dan menjaga kualitas layanannya dengan baik. Sebab, hanya dengan cara meningkatkan atau menjaga kualitas layanan yang baik, maka hubungan dengan para pelanggan dapat dipertahankan secara terus-menerus. Sangkring Art Space (SAS) merupakan salah satu galeri seni yang ada di Yogyakarta. Sejak awal berdiri hingga saat ini, SAS rutin mengadakan pameran untuk memenuhi kebutuhan para perupa (pelanggan) yang berpameran di SAS. Penelitian ini difokuskan untuk menganalisis kualitas layanan yang disediakan Galeri SAS. Penelitian ini menggunakan pendekatan kuantitatif yaitu metode penelitian survei dengan alat SERVQUAL oleh Parasuraman dkk (1988). Rancangan penelitian yang digunakan ialah studi potong lintang (cross-sectional) dan populasi yang diminati ialah pelanggan Galeri SAS. Metode pengambilan sampel dilakukan secara tidak acak (non-probability sampling), yaitu berjumlah 40 orang responden, terdiri dari laki-laki dan perempuan dewasa berusia di atas 25 tahun yang berpameran di Galeri SAS. Berdasarkan penelitian ini, ditemukan hasil, nilai ekspektasi sebesar 5.61 dan nilai persepsi sebesar 5.54. Dengan demikian dapat disimpulkan bahwa bahwa ekspektasi melebihi persepsi pelanggan. Artinya kualitas layanan yang disediakan SAS tidak memenuhi ekspektasi pelanggan.
\end{abstract}

Kata kunci: kualitas layanan, persepsi dan harapan pelanggan, galeri

\begin{abstract}
Talking about galleries as one of the services of engaged in arts, is closely related to the discussion of the quality of its services. Every gallery that wants to progress and develop, is required to always improve and maintain the quality of its services well. Because, only by maintaining good service quality, relationships can be maintained with customers continuously. Sangkring Art Space (SAS) is one of the art galleries in Yogyakarta. Since its inception until now, SAS regularly holds exhibitions to meet the needs of artists (customers) who exhibit in SAS. This study is focused on analyzing the quality of services provided by the SAS gallery. This study uses a quantitative approach, namely survey research methods with SERVQUAL tools by Parasuraman et al (PZB, 1988). The study gallery was used as a crosssectional study and SAS gallery customers. The sampling method was conducted by non-probability sampling, which amounted to 40 respondents, consisting of men and women aged over 25 years who exhibited in the SAS gallery. Based on this study, results were found, the expectation value was 5.61 and the perception value was 5.54. Thus it can be concluded that expectations exceed customer perceptions. This
\end{abstract}


Jurnal Tata Kelola Seni-Vol. 4 No. 1 Juni 2018

p-ISSN 2442-9589, e-ISSN 2614-7009

means that the quality of services provided by SAS does not meet customer expectations

Keywords: quality service, customer perception and expectations, gallery

\section{PENDAHULUAN}

Daerah Istimewa Yogyakarta merupakan salah satu provinsi yang terkenal dengan potensi seni rupanya. Hal tersebut dapat diamati melalui keberadaan seniman atau organisasi seni, pameran-pameran (event), maupun melalui keberadaan galeri seni rupa yang ada di Yogyakarta. Meskipun demikian, berdasarkan grafik seri data Dinas Kebudayaan Daerah Istimewa Yogyakarta Tahun 2013 sampai dengan 2017, galeri seni rupa di Yogyakarta mengalami penurunan dari angka 30 galeri pada tahun 2013 menjadi 29 galeri pada tahun 2014, 2015, 2016, dan 2017. Sedangkan organisasi seni rupa justru sebaliknya mengalami peningkatan dari angka 16 pada tahun 2013, meningkat menjadi 17 pada tahun 2014, 2015, 2016, dan 2017 (https://yogyakarta.bps.go.id). Data statistik di atas mengindikasikan bahwa dalam empat tahun terakhir, pertumbuhan galeri seni rupa di Daerah Istimewa Yogyakarta mengalami stagnasi. Di samping itu, angka-angka di atas juga menunjukkan kesenjangan antara jumlah organisasi dan galeri seni rupa di Yogyakarta.

Seiring dengan tumbuh dan meningkatnya minat para seniman terhadap penggunaan jasa galeri sebagai ruang berpameran di Yogyakarta, maka salah satu masalah yang cenderung muncul yaitu mengenai kualitas layanan galeri. Menurut Putra dalam Wijayanto, "beberapa sarana kesenian seperti Bentara Budaya Yogyakarta dilihat kurang memenuhi kebutuhan seniman untuk berapresiasi dalam karya-karyanya, tidak lain karena banyaknya seniman yang ingin berpameran dalam Bentara Budaya Yogyakarta, sehingga harus menunggu begitu lama dalam pameran yang akan diselenggarakan" (Wijayanto, 2017:2).

Adapun dampak dari kualitas layanan yang dianggap kurang memuaskan yaitu dapat membuat seniman untuk memilih melakukan pameran di galeri lain atau melakukan pameran secara sendiri atau bersama komunitas. Karena itu, untuk mendukung keberlangsungan berbagai aktivitas seni rupa di Yogyakarta, maka kualitas layanan galeri merupakan masalah penting yang perlu diperhatikan dan dievaluasi secara berkala. Sebab, hanya dengan cara meningkatkan dan menjaga kualitas layanan yang baik, maka hubungan dengan para pelanggan (seniman) dapat dipertahankan secara terus-menerus.

Sehubungan dengan hal itu, Buchari Alma menyebutkan bahwa, "sebuah perusahaan jasa harus menjaga kualitas jasa yang ditawarkan harus berada di atas saingan dan lebih hebat dari yang dibayangkan oleh konsumen. Apabila kualitas jasa yang diterima oleh konsumen lebih baik atau sama dengan yang ia bayangkan, maka ia cenderung akan mencobanya kembali. Akan tetapi, bila perceived services lebih rendah dari expected services, maka konsumen akan kecewa dan akan menyetop hubungannya dengan perusahaan jasa yang bersangkutan" (Alma, 2011:282).

Maka dari itu, jika suatu galeri tidak mampu menjaga kualitas pelayanannya dengan baik, maka dapat memungkinkan pelanggan untuk pindah ke pesaing. Dalam hal ini, Rangkuti menjelaskan bahwa, "salah satu akibat dari masalah pelayanan yaitu 
memungkinkan pelanggan untuk pindah ke pesaing lima kali lebih besar dibandingkan dengan masalah-masalah yang berhubungan dengan produk dan harga. Selain itu biaya yang dibutuhkan untuk mencari pelanggan baru lima kali lebih mahal dibandingkan dengan mempertahankan pelanggan yang sudah ada" (Rangkuti, 2013:116). Karena itu, agar sebuah galeri mampu mempertahankan hubungan yang baik dengan para pelanggannya secara terus-menerus dan agar pelanggan tidak beralih ke pesaing, maka kualitas layanan yang disediakan galeri harus selalu ditingkatkan.

Galeri merupakan suatu ruangan yang digunakan untuk menampilkan karya-karya seni (Cyril, 2006:451). Sedangkan menurut Mike, galeri merupakan tempat seniman pameran atau jualan karya seni rupa (Mike, 2011:45). Artinya, galeri bisa bertujuan ideal (bersifat non-komersial) maupun yang komersial dengan tujuan menjual karya (Wijayanto, 2017:2). Pada galeri seni rupa, biasanya karya-karya yang dipamerkan di antaranya yaitu lukisan, patung, seni instalasi, dan seni grafis. Adapun konsep yang digunakan oleh suatu organisasi terhadap galeri sebagai ruang pamer biasanya memiliki pelabelan (merek) yang berbeda-beda. Beberapa organisasi seni di Yogyakarta ada yang menamainya dengan istilah kamar/art room (misalnya Tahunmas Artroom, Wangi Artroom); atau rumah (misalnya Rumah Seni Cemeti, Rumah Seni Sidoarum); atau studio (misalnya Kersan Art Studio, Studio Kalahan, Studio Grafis Minggiran) dan ada juga yang menggunakan istilah Art Space (seperti Pendhapa Art Space, Sewon Art Space, dan Sangkring Art Space).

Sangkring Art Space merupakan salah satu organisasi atau galeri seni yang ada di Yogyakarta. Galeri Sangkring Art Space didirikan oleh Putu Sutawijaya, diresmikan pada tanggal 31 Mei 2007 di Dusun Nitiprayan, Ngestiharjo, Bantul, Daerah Istimewa Yogyakarta (https://sangkringart.com). Heri Wijayanto menyebutkan bahwa "Sangkring Art Space merupakan galeri (swasta) yang tidak berbadan hukum, kegiatan pameran yang diselenggarakan lebih mencakup pada semua ragam karya seni. Manajemen Sangkring Art Space secara umum memiliki tujuan untuk mewadahi seluruh seniman khususnya seniman muda dan seniman yang profesional" (Wijayanto, 2017). Adapun pameran yang pernah dilakukan Sangkring Art Space di antaranya ialah "Tribute to Young Artist" tahun 2007; "Ruang Berikutnya" tahun 2010; "Vibrant Vision Lempad" 2012; "Membatalkan Keperempuanan" 2012; "Yogya Annual Art\#2" 2017; "The Gift" 2017; dan "Biru Emas Ibu Negeri” 2017 (https://sangkringart.com).

Sebagai salah satu galeri seni rupa yang ada di Yogyakarta, Sangkring Art Space tampak berupaya memenuhi kebutuhan pelanggannya secara optimal. Hal tersebut dapat diamati melalui aktivitas pameran yang dilakukan Sangkring Art Space. Berdasarkan observasi tentang keberadaan dan frekuensi pameran yang telah dilakukan Sangkring Art Space selama sepuluh tahun terakhir (2007-2017), muncul dugaan awal bahwa organisasi Sangkring Art Space mampu bertahan dengan cara memenuhi kebutuhan para pelanggannya.

Namun, untuk mengetahui kualitas layanan yang disediakan Sangkring Art Space secara objektif dan sistematis, perlu dilakukan sebuah penelitian terkini. Penelitian ini ingin mengukur kualitas layanan Galeri Sangkring Art Space menggunakan alat SERVQUAL oleh Parasuraman, dkk (1988). Adapun manfaat dari penelitian ini, secara khusus dapat digunakan oleh manajemen Sangkring Art Space untuk meningkatkan kualitas layanan yang disediakan terhadap pelanggannya. Dengan demikian, pertanyaan penelitian yang 
Jurnal Tata Kelola Seni-Vol. 4 No. 1 Juni 2018

p-ISSN 2442-9589, e-ISSN 2614-7009

diajukan ialah bagaimana persepsi dan harapan pelanggan terhadap kualitas layanan galeri Sangkring Art Space.

\section{LANDASAN TEORI}

Kualitas layanan (service quality) merupakan sebuah istilah yang terdiri dari penggabungan dua kata yang berbeda yakni kualitas (quality) dan layanan (service). Menurut Garvin dan David dalam Nasution, kualitas (quality) adalah "kondisi dinamis yang berhubungan dengan produk, manusia/tenaga kerja, proses dan tugas serta lingkungan yang memenuhi atau melebihi harapan pelanggan atau konsumen" (Nasution, 2004:41). Sedangkan jasa atau layanan menurut Kotler dalam Nasution yaitu "setiap tindakan atau perbuatan yang dapat ditawarkan oleh suatu pihak kepada pihak lain yang pada dasarnya intangible (tidak berwujud fisik) dan tidak mengakibatkan kepemilikan apapun, produksi jasa mungkin berkaitan dengan produk fisik atau tidak" (Nasution, 2004:6).

Sementara itu, Parasuraman, Zeithaml, dan Berry dalam Parasuraman dkk (1988) menyebutkan bahwa kualitas layanan, sebagaimana dipersepsikan oleh konsumen, berasal dari perbandingan layanan apa yang menurut mereka harus ditawarkan oleh perusahaan (yaitu, dari harapan mereka) dengan persepsi mereka tentang kinerja perusahaan yang menyediakan layanan (Parasuraman dkk, 1988:16).

Berdasarkan penjelasan di atas, dapat dipahami bahwa kualitas layanan pada sebuah galeri merupakan hubungan antara dua belah pihak yakni antara manajemen galeri dengan pelanggan galeri, yang dapat diukur melalui kesenjangan persepi (yang dirasakan) dan ekpektasi (yang diharapkan) pelanggan terhadap kualitas layanan yang disediakan galeri tersebut.

Robbins dan Coulter menyebutkan bahwa "persepsi merupakan proses di mana kita mengartikan lingkungan sekitar dengan menyusun dan menginterpretasikan impresi sensoris. Penelitian tentang persepsi secara konsisten menunjukkan bahwa setiap orang bisa melihat hal yang sama tetapi berbeda mempersepsikannya" (Robbins dan Coulter, 2010:54). Sementara itu, menurut Zeithaml dalam Parasuraman dkk (1988) menyebutkan bahwa persepsi kualitas adalah penilaian konsumen tentang keunggulan atau superioritas keseluruhan entitas - berbeda dengan kualitas yang bersifat objektif (Parasuraman dkk, 1988:15). Sedangkan, 'kualitas layanan yang dirasakan' (perceived service quality) didefinisikan sebagai tingkat dan arah perbedaan antara persepsi dan harapan konsumen (Parasuraman dkk, 1988:17).

SERVQUAL adalah sebuah alat atau skala multi-item (lima dimensi) yang umum digunakan untuk mengukur persepsi pelanggan tentang kualitas layanan. Sehubungan dengan itu, Parasuraman dkk (1988) menjelaskan sebagai berikut:

"SERVQUAL adalah skala multi-item ringkas dengan keandalan dan validitas yang baik yang dapat digunakan pengecer untuk lebih memahami ekspektasi layanan dan persepsi konsumen dan, sebagai hasilnya, meningkatkan layanan. Instrumen telah dirancang untuk dapat diterapkan di berbagai spektrum layanan. Dengan demikian, ia menyediakan kerangka dasar melalui format ekspektasi/persepsi yang mencakup pernyataan untuk masing-masing dari lima dimensi kualitas layanan. Kerangka, bila perlu, dapat diadaptasi atau ditambahkan agar sesuai dengan karakteristik atau 
kebutuhan penelitian spesifik dari organisasi tertentu" (Parasuraman dkk, 1988:30-31).

Adapun lima dimensi SERVQUAL yang dimaksud Parasuraman dkk (1988) ialah sebagai berikut:

1. Tangibles: fasilitas fisik, peralatan, dan penampilan karyawan.

2. Reliability: kemampuan untuk melakukan layanan yang dijanjikan dapat diandalkan dan akurat.

3. Responsiveness: kesediaan untuk membantu pelanggan dan memberikan layanan yang cepat.

4. Assurance: pengetahuan dan kesopanan karyawan dan kemampuan mereka untuk menginspirasi kepercayaan dan kepercayaan diri.

5. Empathy: peduli, perhatian individual yang diberikan perusahaan kepada pelanggannya.

Selanjutnya Parasuraman dkk (1988) menegaskan sebagai berikut:

"SERVQUAL dapat digunakan untuk menilai kualitas perusahaan tertentu di sepanjang masing-masing dari lima dimensi layanan dengan rata-rata skor perbedaan pada item yang membentuk dimensi. Ini juga dapat memberikan ukuran keseluruhan kualitas layanan dalam bentuk skor rata-rata di kelima dimensi. Karena tanggapan yang bermakna terhadap pernyataan persepsi mengharuskan responden untuk memiliki pengetahuan atau pengalaman dengan perusahaan yang diteliti, SERVQUAL terbatas pada pelanggan saat ini atau masa lalu dari perusahaan itu. Dalam batasan ini, berbagai aplikasi potensial tersedia" (Parasuraman dkk, 1988: 30-31).

\section{METODE}

Penelitian ini menggunakan pendekatan kuantitatif yaitu metode penelitian survei dengan alat SERVQUAL. Menurut Parasuraman dkk (1991), SERVQUAL adalah alat untuk mengukur persepsi pelanggan terhadap kualitas layanan (Parasuraman dkk, 1991:420). Sedangkan penelitian survei yaitu serangkaian metode sistematis yang digunakan untuk mengumpulkan informasi dalam menghasilkan pengetahuan dan membantu membuat keputusan (Lavrakas, 2008: xxxv). Demack (2009) mendefinisikan survei sebagai berikut:

"Survei adalah metode penelitian di mana populasi yang diminati dijadikan sampel. Unit sampel ini kemudian diukur secara sistematis. Pengukuran yang diambil berasal dari penerjemahan masalah penelitian ke dalam hipotesis, dan komponen hipotesis ini dioperasionalkan ke dalam istilah atau pertanyaan yang dapat diukur. Data yang dikumpulkan dianalisis dan digunakan untuk mengeksplorasi hipotesis dalam sampel. Hasil analisis disimpulkan dari sampel ke populasi awal dengan menggunakan uji hipotesis" (Demack, 2009: 6-7).

Pada penelitian ini, rancangan penelitian yang digunakan ialah studi potong lintang (cross-sectional). Hal tersebut dilakukan atas dasar keterbatasan waktu penelitian yang tersedia. Menurut Cong Liu dalam buku "Encyclopedia of Survey Research Methods", cross-sectional atau studi potong lintang adalah "data yang dikumpulkan dari partisipan 
pada satu titik waktu. Waktu tidak dianggap sebagai salah satu variabel penelitian dalam desain penelitian cross-sectional. Namun, perlu dicatat bahwa dalam studi cross-sectional, semua partisipan tidak memberikan data pada saat yang tepat. Bahkan dalam satu sesi, seorang partisipan akan mengisi kuesioner selama jangka waktu tertentu. Meskipun demikian, data cross-sectional biasanya dikumpulkan dari responden yang menyusun sampel dalam jangka waktu yang relatif singkat (periode lapangan). Dalam studi crosssectional, waktu diasumsikan memiliki efek acak yang hanya menghasilkan varian, bukan bias" (Liu, 2008: 170-171).

Adapun populasi yang diminati dalam penelitian ini ialah para perupa (pelanggan) Galeri Sangkring Art Space Yogyakarta. Metode pengambilan sampel dilakukan secara tidak acak (nonprobability sampling), yaitu berjumlah 40 orang responden, terdiri dari lakilaki dan perempuan dewasa (berusia di atas 25 tahun) yang berpameran di Galeri Sangkring Art Space sebanyak lebih dari satu kali. Adapun alasan untuk pengambilan sampel dengan usia respondennya di atas 25 tahun, disesuaikan berdasarkan alat SERVQUAL yang digunakan (lihat Parasuraman dkk, 1985 dan 1988). Sedangkan alasan untuk kategori pelanggan ialah sebagai upaya penyaringan pada populasi yang dijadikan sebagai sampel. Tujuannya yaitu agar sampel yang diambil benar-benar memiliki pengalaman yang cukup untuk mempersepsikan kualitas layanan pada Galeri Sangkring Art Space tersebut. Berikut penjelasan tentang langkah-langkah penelitian yang dilakukan:

1. Persiapan survei: merumuskan masalah penelitian serta menyusun variabel yang akan dipakai dalam penelitian; membuat pertanyaan penelitian; menentukan desain penelitian; pengambilan sampel dari populasi yang menjadi minat dalam penelitian; alat yang akan digunakan; survei di lapangan (pengumpulan data); analisis data, dan interpretasi.

2. Surat izin survei: surat izin survei tidak dibuat secara tertulis tetapi disampaikan secara lisan kepada pemilik Galeri Sangkring Art Space yaitu pada tanggal 5 Oktober 2017 di galeri tersebut.

Setelah itu, penulis menentukan organisasi dan lokasi penelitian yang akan dipilih. Adapun Sangkring Art Space merupakan salah satu galeri yang dianggap sesuai dengan alat SERVQUAL yang digunakan. Alasannya ialah karena Galeri Sangkring Art Space merupakan salah satu galeri seni yang bersifat swasta dan profesional. Selanjutnya, penulis menerjemahkan alat (kuesioner) yaitu SERVQUAL yang dibuat oleh Parasuraman dkk (1988). Setelah diperiksa, kemudian diujikan pada teman-teman terdekat terlebih dahulu; masukan dari teman-teman mahasiswa dicatat dan kuesioner diperbaiki.

Pada proses selanjutnya alat (kuesioner) didiskusikan ulang di dalam kelas metode penelitian. Pada tahap itu terdapat koreksi pada susunan dan terjemahan yang penulis lakukan, maka kuesioner diperbaiki sekali lagi dan disesuaikan dengan alat aslinya.

Tahap selanjutnya adalah administrasi survei di lapangan (pengumpulan data). Sebelum melakukan survei di lapangan, terlebih dahulu penulis membuat protokol yang dijadikan sebagai panduan dalam membagikan kuesioner. Proses pembagian kuesioner dilakukan secara dua tahap. Pada tahap pertama, kuesioner disebarkan pada tanggal 7 dan 8 Oktober 2017 di beberapa tempat yaitu Galeri Sangkring Art Space, rumah responden dan di warung tempat responden biasa berkumpul. Penyebaran kuesioner tahap pertama dilakukan oleh penulis dan dibantu oleh beberapa orang petugas yakni Ferry, Jalu, dan Susi. 
Ketiga orang petugas merupakan teman penulis di jurusan tata kelola seni Program Pascasarjana Institut Seni Indonesia Yogyakarta angkatan 2017/2018. Alasannya ialah karena petugas merasa dekat dengan para pelanggan Sangkring Art Space. Maka dari itu, mereka menawarkan diri untuk membagikan kuesioner pada teman-temannya, para perupa yang berpameran di Sangkring Art Space. Sebelum membagikan kuesioner, terlebih dahulu petugas membuat janji dengan beberapa perupa yang teridentifikasi sebagai pelanggan Galeri Sangkring Art Space tersebut. Adapun hasil pengumpulan data tahap pertama terdapat 7 orang responden yang bersedia mengisi kuesioner.

Selanjutnya, pada tahap kedua, kuesioner disebarkan pada tanggal 11, 12, 13, 14, dan 15 Oktober 2017 di dua tempat yakni di Galeri Sangkring Art Space dan di rumah atau tempat tinggal responden. Pada tahap kedua, penyebaran kuesioner dilakukan oleh empat orang petugas yaitu penulis, Jalu, Ferry, dan Susi. Pada tahap kedua ini, terdapat 33 orang responden yang bersedia mengisi kuesioner. Pada dasarnya pembagian kuesioner tahap dua dilakukan dengan cara mengidentifikasi nama-nama responden serta mengunjungi galeri pada saat pameran berlangsung. Adapun daftar nama para perupa didapatkan melalui berbagai informasi, di antaranya yaitu katalog atau brosur-brosur pameran yang pernah dilakukan Sangkring Art Space dan juga informasi dari perupa yang pernah berpameran di Galeri Sangkring Art Space. Alasan penulis melakukan cara tersebut ialah karena menurut penulis cara ini selain mudah juga tepat pada sasarannya.

Adapun hasil dari pengumpulan data secara keseluruhan, jumlah responden yang didapatkan ialah sebanyak 40 orang responden dan rata-rata waktu pengisian kuesioner yaitu 8 menit 52 detik. Setelah penulis melakukan pengumpulan data, tahap selanjutnya ialah menganalisis data. Data-data yang telah terkumpul diberi nomor dan diurutkan berdasarkan tanggal pengumpulan serta petugasnya. Setelah diurutkan, maka proses selanjutnya yaitu perekaman data. Data direkam dan diinput ke dalam Microsoft Excel menggunakan laptop oleh penulis dan petugas.

\section{ANALISIS DATA}

Analisis data dilakukan oleh penulis dan petugas. Data-data yang telah dianalisis diperiksa kembali dengan cara dibacakan ulang secara satu per satu oleh petugas untuk memastikan bahwa rumus-rumus excel yang digunakan oleh masing-masing petugas adalah benar dan tepat. Adapun hasil analisis data bisa dilihat pada tabel-tabel di bawah ini:

Tabel 1. Nilai Rata-rata Variabel Ekpektasi dan Persepsi

\begin{tabular}{|c|c|c|}
\hline Item & Ekspektasi & Persepsi \\
\hline $\mathbf{1}$ & 5.43 & 5.63 \\
\hline $\mathbf{2}$ & $\mathbf{5 . 9 5}$ & 5.85 \\
\hline $\mathbf{3}$ & $\mathbf{5 . 2 0}$ & $\mathbf{4 . 8 8}$ \\
\hline $\mathbf{4}$ & 5.88 & 5.88 \\
\hline $\mathbf{5}$ & 5.75 & 5.75 \\
\hline $\mathbf{6}$ & 5.55 & 5.70 \\
\hline $\mathbf{7}$ & 5.78 & 5.53 \\
\hline $\mathbf{8}$ & 5.80 & 5.73 \\
\hline
\end{tabular}




\begin{tabular}{|c|c|c|}
\hline $\mathbf{9}$ & 5.45 & 5.28 \\
\hline $\mathbf{1 0}$ & 5.73 & 5.58 \\
\hline $\mathbf{1 1}$ & 5.68 & 5.75 \\
\hline $\mathbf{1 2}$ & 5.63 & 5.65 \\
\hline $\mathbf{1 3}$ & 5.38 & 5.40 \\
\hline $\mathbf{1 4}$ & 5.88 & 5.58 \\
\hline $\mathbf{1 5}$ & 5.73 & 5.45 \\
\hline $\mathbf{1 6}$ & 5.58 & 5.13 \\
\hline $\mathbf{1 7}$ & 5.90 & 5.98 \\
\hline $\mathbf{1 8}$ & 5.43 & 5.33 \\
\hline $\mathbf{1 9}$ & 5.48 & 5.58 \\
\hline $\mathbf{2 0}$ & 5.25 & 5.03 \\
\hline $\mathbf{2 1}$ & 5.58 & 5.63 \\
\hline $\mathbf{2 2}$ & 5.58 & 5.58 \\
\hline
\end{tabular}

Angka paling tinggi

Angka paling rendah

Tabel 2. Nilai Rata-rata Dimensi Ekspektasi dan Persepsi

\begin{tabular}{|l|c|c|c|c|c|}
\hline & Tangible & Reliability & Responsiveness & Assurance & Empathy \\
\hline Ekpektasi & 5.61 & 5.66 & 5.60 & 5.77 & 5.46 \\
\hline Persepsi & 5.56 & 5.59 & 5.59 & 5.53 & 5.43 \\
\hline
\end{tabular}

Tabel 3. Nilai Kesenjangan Item (P-E)

\begin{tabular}{|c|c|c|c|}
\hline Item & Ekspektasi & Persepsi & Hasil (P-E) \\
\hline $\mathbf{1}$ & 5.43 & 5.63 & 0.20 \\
\hline $\mathbf{2}$ & 5.95 & 5.85 & -0.10 \\
\hline $\mathbf{3}$ & 5.20 & 4.88 & -0.33 \\
\hline $\mathbf{4}$ & 5.88 & 5.88 & 0.00 \\
\hline $\mathbf{5}$ & 5.75 & 5.75 & 0.00 \\
\hline $\mathbf{6}$ & 5.55 & 5.70 & 0.15 \\
\hline $\mathbf{7}$ & 5.78 & 5.53 & -0.25 \\
\hline $\mathbf{8}$ & 5.80 & 5.73 & -0.08 \\
\hline $\mathbf{9}$ & 5.45 & 5.28 & -0.18 \\
\hline $\mathbf{1 0}$ & 5.73 & 5.58 & -0.15 \\
\hline $\mathbf{1 1}$ & 5.68 & 5.75 & 0.08 \\
\hline $\mathbf{1 2}$ & 5.63 & 5.65 & 0.03 \\
\hline $\mathbf{1 3}$ & 5.38 & 5.40 & 0.03 \\
\hline $\mathbf{1 4}$ & 5.88 & 5.58 & -0.30 \\
\hline $\mathbf{1 5}$ & 5.73 & 5.45 & -0.27 \\
\hline $\mathbf{1 6}$ & 5.58 & 5.13 & -0.45 \\
\hline $\mathbf{1 7}$ & 5.90 & 5.98 & 0.07 \\
\hline $\mathbf{1 8}$ & 5.43 & 5.33 & -0.10 \\
\hline
\end{tabular}




\begin{tabular}{|l|l|l|l|}
\hline $\mathbf{1 9}$ & 5.48 & 5.58 & 0.10 \\
\hline $\mathbf{2 0}$ & 5.25 & 5.03 & -0.23 \\
\hline $\mathbf{2 1}$ & 5.58 & 5.63 & 0.05 \\
\hline $\mathbf{2 2}$ & 5.58 & 5.58 & 0.00 \\
\hline
\end{tabular}

Tabel 4. Nilai Rata-rata Keseluruhan Ekpektasi dan Persepsi

\begin{tabular}{|l|c|}
\hline Ekpektasi & 5.61 \\
\hline Persepsi & 5.54 \\
\hline
\end{tabular}

\section{INTERPRETASI}

1. Variabel/Item

Pada bagian ekspektasi, nilai tertinggi adalah 5.95 terdapat pada item E2 yaitu "fasilitas fisik (seperti ruang pameran, toilet, warung kopi) pada Sangkring Art Space yang terbaik selalu menarik secara visual". Sedangkan nilai terendah adalah 5.20 terdapat pada item E3 yaitu "karyawan Sangkring Art Space terbaik selalu tampil rapi". Pada bagian persepsi nilai tertinggi adalah 5.98 terdapat pada item P17 yaitu "karyawan Sangkring Art Space memiliki pengetahuan untuk menjawab pertanyaan Anda". Sedangkan nilai terendah adalah 4.88 terdapat pada item P3 yaitu "karyawan Sangkring Art Space tampil rapi".

2. Dimensi

Pada bagian ekspektasi, jika angka diurutkan dari yang paling rendah ke yang paling tinggi, maka hasilnya ialah 5.46 (empathy), 5.60 (responsiveness), 5.61 (tangible), 5.66 (reliability), dan 5.77 (assurance). Sedangkan pada bagian persepsi hasilnya ialah 5.43 (empathy), 5.53 (assurance), 5.56 (tangible), 5.59 (reliability), dan 5.59 (responsiveness). Berdasarkan data di atas dapat dibandingkan bahwa, dimensi assurance lebih tinggi dari reliability; reliability lebih tinggi dari tangible; tangible lebih tinggi dari responsiveness; responsiveness lebih tinggi dari empathy; dan empathy merupakan dimensi yang paling rendah di antara semua dimensi pada ekspektasi pelanggan. Di samping itu, pada bagian persepsi dimensi responsiveness dan reliability bernilai sama dan lebih tinggi dari tangible; tangible lebih tinggi dari assurance; assurance lebih tinggi dari emphaty; dan empathy merupakan dimensi paling rendah pada bagian persepsi.

3. Kesenjangan (P-E)

Berdasarkan analisis pada kesenjangan per item, ditemukan dua kategori yaitu persepsi sama besar dengan ekspektasi pelanggan dan ekspektasi lebih besar dari persepsi pelanggan (minus/tidak memenuhi harapan). Adapun item-item yang termasuk pada kategori pertama terdiri dari P1, P4, P5, P6, P11, P12, P13, P17, P19, P21, dan P22. Sedangkan, untuk kategori kedua (minus) terdiri dari P2, P3, P7, P8, P9, P10, P14, P15, P16, P18, dan P20.

4. Keseluruhan

Berdasarkan analisis data secara keseluruhan (per bagian), maka hasil yang ditemukan adalah nilai ekspektasi 5.61 dan nilai persepsi 5.54. Berdasarkan data itu, dapat ditarik kesimpulan bahwa ekspektasi melebihi persepsi pelanggan Galeri Sangkring Art Space dengan selisih nilai 6 angka. Dengan demikian, untuk memenuhi harapan pelanggan, organisasi Sangkring Art Space perlu meningkatkan kualitas layanannya. 


\section{KESIMPULAN}

Berdasarkan data-data di atas, dapat ditarik kesimpulan bahwa ekspektasi melebihi persepsi pelanggan. Artinya hal tersebut mengindikasikan bahwa kualitas layanan yang disediakan organisasi Sangkring Art Space tidak memenuhi harapan pelanggan. Maka dari itu, untuk memperbaiki kualitas layanan tersebut, penulis menyarankan agar organisasi Sangkring memperhatikan kesenjangan-kesenjangan pada lapisan bawah yakni pada itemitem yang tidak memenuhi harapan tersebut. Sebagai contoh kesenjangan ekspektasi lebih tinggi dari persepsi pelanggan terdapat pada item E2 (5.95) dan P2 (5.85). Dengan demikian, organisasi perlu memperhatikan dan meningkatkan kualitas layanan terhadap fasilitas fisik (ruang pameran, toilet, warung kopi) pada Galeri Sangkring Art Space.

Sedangkan pada lapisan tengah (dimensi), data menunjukkan bahwa semua dimensi tidak memenuhi harapan pelanggan. Adapun kesenjangan dimensi yang paling tinggi terdapat pada assurance (lihat tabel 2). Kesenjangan pada dimensi assurance ini menunjukkan bahwa item-item yang paling penting untuk diperbaiki yaitu terdapat pada item P14 "perilaku karyawan Sangkring Art Space akan menanamkan kepercayaan pada pelanggan", P15 "pelanggan merasa aman dalam bertransaksi dengan Sangkring Art Space" dan P16 "karyawan Sangkring Art Space secara konsisten berlaku sopan dengan pelanggan".

\section{SARAN}

Karena populasi yang diminati pada penelitian ini terbatas pada pelanggan Galeri Sangkring Art Space, maka pada akhirnya manfaat penelitian ini juga terbatas untuk Galeri Sangkring Art Space. Karena itu, agar kualitas layanan galeri seni rupa di Yogyakarta dapat digeneralisasi, maka penulis menyarankan agar penelitian selanjutnya mengukur kualitas layanan galeri pada sampel yang lebih besar, yaitu pada para pelanggan galerigaleri yang ada di Yogyakarta, tidak terbatas pada satu atau dua galeri saja.

\section{KEPUSTAKAAN}

Alma, Buchari. 2011. Manajemen Pemasaran dan Pemasaran Jasa. Bandung: Alfabeta. Demack, Sean. 2009. The Fundamentals of Survey Data Analysis. Sheffield Hallam University. 6-7

Lavrakas, Paul. J. 2008. Encyclopedia of Survey Research Methods. Sage Publication.

Liu, Cong. 2008. Encyclopedia of Survey Research Methods. Sage Publication.

M. Harris, Cyril. 2006. Dictionary of Architecture and Construction. Four Edition. New York: McGraw-Hill Companies.

Nasution, M.N. 2004. Manajemen Jasa Terpadu: Total Service Management. Bogor: Ghalia Indonesia.

Parasuraman dkk. 1991. "Refinement and Reassessment of the SERVQUAL Scale". Journal of Reatiling, Vol. 67 No. 4. Winter. 420.

Parasuraman dkk. 1988. "SERVQUAL: Multiple-Item Scale for Measuring Consumer Perceptions of Service Quality”. Journal of Reatiling. Vol. 64 No. 1. Spring. 1540.

Rangkuti, Freddy. 2013. Customer Service Satisfaction \& Call Center Berdasarkan ISO 9001. Jakarta: PT. Gramedia Pustaka Utama.

Robbins and Coulter. 2010. Manajemen Edisi Kesepuluh. Jakarta: Erlangga. 
Susanto, Mike. 2011. Diksi Rupa: Kumpulan Istilah dan Gerakan Seni Rupa. Yogyakarta: Dictiart Lab \& Jagad Art House.

Wijayanto, Heri. 2017. "Seniman Sebagai Pemilik Galeri: Studi Komparasi Antara Tiga Manajemen Galeri Swasta di Yogyakarta”. Yogyakarta: Manajemen Tata Kelola

Situs Web

Seni Institut Seni Indonesia Yogyakarta. 2-11

http://sangkringart.com/profile-3/sangkring-art-space/

https://yogyakarta.bps.go.id

\section{LAMPIRAN}

\section{KUESIONER \\ PERSEPSI DAN EKPEKTASI PELANGGAN TERHADAP KUALITAS \\ LAYANAN DI GALERI SANGKRING ART SPACE}

* Penelitian ini merupakan tugas matakuliah metode penelitian mahasiswa Program Magister di Institut Seni Indonesia, Yogyakarta. Pernyataan pada bagian I mengenai ekspektasi atau harapan pelanggan terhadap kualitas layanan Sangkring Art Space dan Bagian II mengenai persepsi pelanggan.

* Kami meminta Anda meluangkan waktu sebentar untuk mengisi/melingkari pernyataan berikut, semua respons akan dijaga kerahasiaannya.

\section{Bagian I. Ekspektasi (E)}

\section{Petunjuk pengisian kuesioner}

Berdasarkan pengalaman Anda sebagai pelanggan di Galeri Sangkring Art Space, tolong tunjukkan sejauhmana menurut Anda Sangkring Art Space harus memiliki keunggulan atau fitur yang dijelaskan oleh setiap pernyataan yang disediakan. Jika Anda merasa keunggulan atau fiturnya sama sekali tidak penting bagi kebaikan Sangkring Art Space, lingkari nomor "1". Jika Anda merasa keunggulan atau fiturnya sangat penting bagi kebaikan Sangkring Art Space, lingkari "7". Jika Anda merasa biasa-biasa saja (netral), lingkari salah satu angka di tengah. Tidak ada jawaban benar atau salah - semua yang ingin kami ketahui adalah angka yang benar-benar mencerminkan perasaan Anda mengenai Sangkring Art Space dalam memberikan kualitas layanan yang terbagus/terbaik.

\begin{tabular}{|l|l|lllllcc|}
\hline NO & \multicolumn{1}{|c|}{ SOAL } & \multicolumn{1}{|c|}{ STS } & & & SS \\
\hline E1 & $\begin{array}{l}\text { Sangkring Art Space yang terbaik memiliki peralatan terbaru } \\
\text { (seperti lampu, kursi, dan alat-alat untuk memajang lukisan). }\end{array}$ & 1 & 2 & 3 & 4 & 5 & 6 & 7 \\
\hline E2 & $\begin{array}{l}\text { Fasilitas fisik (seperti ruang pameran, toilet, warung kopi) pada } \\
\text { Sangkring Art Space yang terbaik selalu menarik secara visual. }\end{array}$ & 1 & 2 & 4 & 5 & 6 & 7 \\
\hline E3 & Karyawan Sangkring Art Space terbaik selalu tampil rapi. & 1 & 2 & 3 & 4 & 5 & 6 & 7 \\
\hline E4 & $\begin{array}{l}\text { Materi yang terkait dengan layanan (seperti katalog atau } \\
\text { informasi penting lainnya) selalu menarik secara visual di } \\
\text { Galeri Sangkring Art Space. }\end{array}$ & 1 & 2 & 3 & 4 & 5 & 6 & 7 \\
\hline E5 & $\begin{array}{l}\text { Ketika Sangkring Art Space berjanji untuk melakukan pameran } \\
\text { lukisan pada suatu waktu tertentu, mereka akan menepatinya. }\end{array}$ & 1 & 2 & 3 & 4 & 5 & 6 & 7 \\
\hline E6 & $\begin{array}{l}\text { Ketika pelanggan memiliki masalah, Sangkring Art Space } \\
\text { menunjukkan keinginan yang tulus untuk menyelesaikannya. }\end{array}$ & 1 & 2 & 4 & 5 & 6 & 7 \\
\hline E7 & $\begin{array}{l}\text { Sangkring Art Space akan melakukan pelayanan dengan benar } \\
\text { untuk pertama kalinya. }\end{array}$ & 1 & 2 & 4 & 5 & 6 & 7 \\
\hline
\end{tabular}




\begin{tabular}{|c|c|c|c|c|c|c|c|c|}
\hline E8 & $\begin{array}{l}\text { Sangkring Art Space akan menyediakan layanan mereka pada } \\
\text { saat mereka berjanji untuk melakukannya. }\end{array}$ & 1 & 2 & 3 & 4 & 5 & 6 & 7 \\
\hline E9 & $\begin{array}{l}\text { Sangkring Art Space akan meyakinkan dengan tegas bahwa } \\
\text { mereka bebas dari kesalahan. }\end{array}$ & 1 & 2 & 3 & 4 & 5 & 6 & 7 \\
\hline E10 & $\begin{array}{l}\text { Karyawan Sangkring Art Space akan memberitahu pelanggan } \\
\text { kapan layanan akan dilakukan. }\end{array}$ & 1 & 2 & 3 & 4 & 5 & 6 & 7 \\
\hline E11 & $\begin{array}{l}\text { Karyawan Sangkring Art Space memberikan pelayanan yang } \\
\text { cepat kepada pelanggan. }\end{array}$ & 1 & 2 & 3 & 4 & 5 & 6 & 7 \\
\hline E12 & $\begin{array}{l}\text { Karyawan Sangkring Art Space akan selalu bersedia membantu } \\
\text { pelanggan. }\end{array}$ & 1 & 2 & 3 & 4 & 5 & 6 & 7 \\
\hline E13 & $\begin{array}{l}\text { Karyawan Sangkring Art Space tidak akan pernah merasa sibuk } \\
\text { untuk menanggapi permintaan pelanggan. }\end{array}$ & 1 & 2 & 3 & 4 & 5 & 6 & 7 \\
\hline E14 & $\begin{array}{l}\text { Perilaku karyawan Sangkring Art Space akan menanamkan } \\
\text { kepercayaan pada pelanggan. }\end{array}$ & 1 & 2 & 3 & 4 & 5 & 6 & 7 \\
\hline E15 & $\begin{array}{l}\begin{array}{l}\text { Pelanggan Sangkring Art Space merasa aman dalam } \\
\text { bertransaksi. }\end{array} \\
\end{array}$ & 1 & 2 & 3 & 4 & 5 & 6 & 7 \\
\hline E16 & $\begin{array}{l}\text { Karyawan Sangkring Art Space secara konsisten berlaku sopan } \\
\text { dengan pelanggan. }\end{array}$ & 1 & 2 & 3 & 4 & 5 & 6 & 7 \\
\hline E17 & $\begin{array}{l}\text { Karyawan Sangkring Art Space memiliki pengetahuan untuk } \\
\text { menjawab pertanyaan pelanggan. }\end{array}$ & 1 & 2 & 3 & 4 & 5 & 6 & 7 \\
\hline E18 & $\begin{array}{l}\text { Sangkring Art Space memberi perhatian kepada pelanggan } \\
\text { secara khusus atau individual. }\end{array}$ & 1 & 2 & 3 & 4 & 5 & 6 & 7 \\
\hline E19 & $\begin{array}{l}\text { Sangkring Art Space memiliki jam pameran lukisan yang } \\
\text { nyaman bagi semua pelanggan mereka. }\end{array}$ & 1 & 2 & 3 & 4 & 5 & 6 & 7 \\
\hline E20 & $\begin{array}{l}\text { Sangkring Art Space memiliki karyawan yang memberi } \\
\text { perhatian secara pribadi kepada pelanggan. }\end{array}$ & 1 & 2 & 3 & 4 & 5 & 6 & 7 \\
\hline $\bar{E} 21$ & $\begin{array}{l}\text { Sangkring Art Space benar-benar peduli pada kepentingan } \\
\text { pelanggan. }\end{array}$ & 1 & 2 & 3 & 4 & 5 & 6 & 7 \\
\hline E22 & $\begin{array}{l}\text { Karyawan Sangkring Art Space memahami kebutuhan khusus } \\
\text { pelanggan mereka. }\end{array}$ & 1 & 2 & 3 & 4 & 5 & 6 & 7 \\
\hline
\end{tabular}

\section{Bagian II. Persepsi (P)}

\section{Petunjuk pengisian kuesioner}

Berdasarkan pengalaman Anda sebagai pelanggan di Galeri Sangkring Art Space, tolong tunjukkan sejauhmana menurut Anda, Sangkring Art Space harus memiliki keunggulan atau fitur yang dijelaskan oleh setiap pernyataan yang disediakan. Jika Anda merasa keunggulan atau fiturnya sama sekali tidak penting bagi kemajuan Sangkring Art Space, lingkari nomor "1". Jika Anda merasa keunggulan atau fiturnya sangat penting bagi kemajuan Sangkring Art Space, lingkari "7". Jika Anda merasa biasa-biasa saja (netral), lingkari salah satu angka di tengah. Tidak ada jawaban benar atau salah - semua yang ingin kami ketahui adalah angka yang benar-benar mencerminkan perasaan Anda mengenai Sangkring Art Space dalam memberikan kualitas layanan yang terbagus/terbaik.

\begin{tabular}{|c|c|c|c|c|c|c|c|}
\hline NO & SOAL & STS & & & & & $\mathrm{S}$ \\
\hline $\mathrm{P} 1$ & $\begin{array}{l}\text { Sangkring Art Space yang terbaik memiliki peralatan terbaru } \\
\text { (seperti lampu, kursi, dan alat-alat untuk memajang lukisan). }\end{array}$ & 2 & 3 & 4 & 5 & 6 & 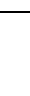 \\
\hline P2 & $\begin{array}{l}\text { Fasilitas fisik (seperti ruang pameran, toilet, warung kopi) pada } \\
\text { Sangkring Art Space yang terbaik selalu menarik secara visual. }\end{array}$ & 2 & 3 & 4 & 5 & ( & 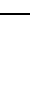 \\
\hline
\end{tabular}




\begin{tabular}{|c|c|c|c|c|c|c|c|c|}
\hline P3 & Karyawan Sangkring Art Space terbaik selalu tampil rapi. & 1 & 2 & 3 & 4 & 5 & 6 & 7 \\
\hline $\mathrm{P} 4$ & $\begin{array}{l}\text { Materi yang terkait dengan layanan (seperti katalog atau } \\
\text { informasi penting lainnya) selalu menarik secara visual di } \\
\text { Galeri Sangkring Art Space. }\end{array}$ & 1 & 2 & 3 & 4 & 5 & 6 & 7 \\
\hline $\mathrm{P} 5$ & $\begin{array}{l}\text { Ketika Sangkring Art Space berjanji untuk melakukan pameran } \\
\text { lukisan pada suatu waktu tertentu, mereka akan menepatinya. }\end{array}$ & 1 & 2 & 3 & 4 & 5 & 6 & 7 \\
\hline P6 & $\begin{array}{l}\text { Ketika pelanggan memiliki masalah, Sangkring Art Space } \\
\text { menunjukkan keinginan yang tulus untuk menyelesaikannya. }\end{array}$ & 1 & 2 & 3 & 4 & 5 & 6 & 7 \\
\hline P7 & $\begin{array}{l}\text { Sangkring Art Space akan melakukan pelayanan dengan benar } \\
\text { untuk pertama kalinya. }\end{array}$ & 1 & 2 & 3 & 4 & 5 & 6 & 7 \\
\hline P8 & $\begin{array}{l}\text { Sangkring Art Space akan menyediakan layanan mereka pada } \\
\text { saat mereka berjanji untuk melakukannya. }\end{array}$ & 1 & 2 & 3 & 4 & 5 & 6 & 7 \\
\hline P9 & $\begin{array}{l}\text { Sangkring Art Space akan meyakinkan dengan tegas bahwa } \\
\text { mereka bebas dari kesalahan. }\end{array}$ & 1 & 2 & 3 & 4 & 5 & 6 & 7 \\
\hline P10 & $\begin{array}{l}\text { Karyawan Sangkring Art Space akan memberitahu pelanggan } \\
\text { kapan layanan akan dilakukan. }\end{array}$ & 1 & 2 & 3 & 4 & 5 & 6 & 7 \\
\hline $\mathrm{P} 11$ & $\begin{array}{l}\text { Karyawan Sangkring Art Space memberikan pelayanan yang } \\
\text { cepat kepada pelanggan. }\end{array}$ & 1 & 2 & 3 & 4 & 5 & 6 & 7 \\
\hline P12 & $\begin{array}{l}\text { Karyawan Sangkring Art Space akan selalu bersedia membantu } \\
\text { pelanggan. }\end{array}$ & 1 & 2 & 3 & 4 & 5 & 6 & 7 \\
\hline P13 & $\begin{array}{l}\text { Karyawan Sangkring Art Space tidak akan pernah merasa sibuk } \\
\text { untuk menanggapi permintaan pelanggan. }\end{array}$ & 1 & 2 & 3 & 4 & 5 & 6 & 7 \\
\hline P14 & $\begin{array}{l}\text { Perilaku karyawan Sangkring Art Space akan menanamkan } \\
\text { kepercayaan pada pelanggan. }\end{array}$ & 1 & 2 & 3 & 4 & 5 & 6 & 7 \\
\hline $\mathrm{P} 15$ & $\begin{array}{l}\text { Pelanggan Sangkring Art Space merasa aman dalam } \\
\text { bertransaksi. }\end{array}$ & 1 & 2 & 3 & 4 & 5 & 6 & 7 \\
\hline P16 & $\begin{array}{l}\text { Karyawan Sangkring Art Space secara konsisten berlaku sopan } \\
\text { dengan pelanggan. }\end{array}$ & 1 & 2 & 3 & 4 & 5 & 6 & 7 \\
\hline P17 & $\begin{array}{l}\text { Karyawan Sangkring Art Space memiliki pengetahuan untuk } \\
\text { menjawab pertanyaan pelanggan. }\end{array}$ & 1 & 2 & 3 & 4 & 5 & 6 & 7 \\
\hline P18 & $\begin{array}{l}\text { Sangkring Art Space memberi perhatian kepada pelanggan } \\
\text { secara khusus atau individual. }\end{array}$ & 1 & 2 & 3 & 4 & 5 & 6 & 7 \\
\hline P19 & $\begin{array}{l}\text { Sangkring Art Space memiliki jam pameran lukisan yang } \\
\text { nyaman bagi semua pelanggan mereka. }\end{array}$ & 1 & 2 & 3 & 4 & 5 & 6 & 7 \\
\hline $\mathrm{P} 20$ & $\begin{array}{l}\text { Sangkring Art Space memiliki karyawan yang memberi } \\
\text { perhatian secara pribadi kepada pelanggan. }\end{array}$ & 1 & 2 & 3 & 4 & 5 & 6 & 7 \\
\hline P21 & $\begin{array}{l}\text { Sangkring Art Space benar-benar peduli pada kepentingan } \\
\text { pelanggan. }\end{array}$ & 1 & 2 & 3 & 4 & 5 & 6 & 7 \\
\hline $\mathrm{P} 22$ & $\begin{array}{l}\text { Karyawan Sangkring Art Space memahami kebutuhan khusus } \\
\text { pelanggan mereka. }\end{array}$ & 1 & 2 & 3 & 4 & 5 & 6 & 7 \\
\hline
\end{tabular}

